\title{
Optimal method for early detection of cardiac disorders in thalassemia major patients: magnetic resonance imaging or echocardiography?
}

\author{
Farideh Moussavi ${ }^{1}$, Mounes Aliyari Ghasabeh ${ }^{2}$, Shahla Roodpeyma ${ }^{3}$, Samin Alavi ${ }^{4}$, Majid Shakiba ${ }^{2}$, Riaz \\ Gheiratmand $^{1}$, Maryam Omidghaemi ${ }^{1}$ \\ ${ }^{1}$ Department of Pediatric Hematology, Shohada Hospital, Shahid Beheshti University of Medical Sciences, ${ }^{2}$ Advanced Diagnostic and \\ Interventional Radiology Research Center, Imam Khomeini Hospital, Keshavarz Boulevard, Tehran University of Medical Sciences, \\ ${ }^{3}$ Pediatric cardiology division, Modarres Hospital, Shahid Beheshti University of Medical Sciences, ${ }^{4}$ Department of Pediatric \\ Hematology, Mofid Hospital, Shahid Beheshti University of Medical Sciences, Tehran, Iran
}

p-ISSN 2287-979X / e-ISSN 2288-0011 http://dx.doi.org/10.5045/br.2014.49.3.182 Blood Res 2014;49:182-6.

Received on February 24, 2014

Revised on July 14, 2014

Accepted on August 18, 2014

\section{Correspondence to}

Mounes Aliyari Ghasabeh, M.D.

Advanced Diagnostic and Interventional

Radiology Research Center, Imam

Khomeini Hospital, Keshavarz Boulevard

Tehran University of Medical Sciences,

P.O. Box 1419733141, Tehran, Iran

Tel: $+98-9123601293$

Fax: +98-22904536

E-mail: mnaliyari@gmail.com

(C) 2014 Korean Society of Hematology

\section{Background}

Heart failure resulting from myocardial iron deposition is the most important cause of death in $\beta$-thalassemia major (TM) patients. Cardiac T2*magnetic resonance imaging (MRI), echocardiography, and serum ferritin level serve as diagnostic methods for detecting myocardial iron overload. In this study, we aimed to evaluate the relationship between the above-mentioned methods.

\section{Methods}

T2*MRI and echocardiographic measurement of left ventricular (LV) systolic and diastolic function were performed in 63 patients. Serum ferritin level was measured. The relationships between all assessments were evaluated.

Results

There were 40 women and 23 men with a mean age of $23.7 \pm 5.1$ years (range, 15-35 years). There was no statistically significant correlation between serum ferritin level and LV systolic and diastolic function ( $P=0.994$ and $P=0.475$, respectively). T2*MRI results had a significant correlation with ferritin level; $63.6 \%$ of patients with serum ferritin level $>2,000 \mathrm{ng} / \mathrm{mL}$ had abnormal cardiac MRI, while none of the patients with ferritin level $<1,000 \mathrm{ng} / \mathrm{mL}$ had abnormal cardiac MRI $(P=0.001)$. There was no significant correlation between MRI findings and LV systolic function $(P=1.00)$. However, we detected a significant difference between LV diastolic function and cardiac siderosis $(P=0.03)$

\section{Conclusion}

MRI findings are a good predictor of future cardiac dysfunction, even in asymptomatic TM patients; however, diastolic dysfunction may happen prior to cardiac siderosis in some patients, and echocardiography is able to diagnose this diastolic dysfunction while T2* MRI shows normal findings.

Key Words Echocardiography, Iron over load, Serum ferritin level, Thalassemia major, T2* MRI

\section{INTRODUCTION}

Impaired synthesis of the $\beta$-globin chain causes an inherited hemoglobin disorder called beta thalassemia, which results in a wide spectrum anemia syndrome ranging from clinically asymptomatic (thalassemia minor) to severe anemia
( $\beta$-thalassemia major $[\mathrm{TM}])[1,2]$.

For normal growth and better quality of life, TM patients need regular blood transfusion to maintain the pre-transfusion hemoglobin level $>9-10.5 \mathrm{~g} / \mathrm{dL}$ [3]. Frequent transfusion results in unavoidable iron overloads [4]. Although iron chelation therapy has become a common and essential part of TM treatment since the 1970s and there is now 
considerable information about effective chelators, myocardial iron deposition, or cardiac siderosis, results in cardiac dysfunction and remains the most important cause of mortality and morbidity in TM patients [5]. It is noteworthy that cardiac complications are the leading cause of mortality in $71 \%$ of TM patients [6]. Early detection of iron deposition in body tissues, especially in the myocardium, is very important for assessment of chelation therapy [7].

Several methods have been introduced to evaluate iron overload. Serum ferritin level is commonly used to assess body iron stores, as it is relatively correlated with iron deposition in organs, but its level may be affected by several other conditions such as the serum level of vitamin $C$ [8]. Cardiac magnetic resonance imaging (MRI) has been used to measure cardiac iron deposition $[9,10]$. MRI measures a parameter called "T2*", which is defined as the rate of loss of signal in tissues that are iron-loaded [11]: increased myocardial iron deposition leads to a decreased $\mathrm{T}^{*}$ value on MRI. T2* $>20 \mathrm{~ms}$ indicates cardiac tissue without iron deposition and no cardiac dysfunction, while $\mathrm{T} 2 *<\mathrm{ms}$ indicates severe cardiac siderosis with a $50 \%$ risk of developing cardiac dysfunction within 1 year [12, 13]. In November 2009, the American Heart Association reported that a cardiac T2* $<10$ ms predicts a cardiac event within 1 year in TM patients with $98 \%$ sensitivity and $86 \%$ specificity [12]. Thus, TM patients need serial MRI throughout their lives to demonstrate the extent of iron deposition and to assess the quality of chelation therapy; nevertheless, MRI is an expensive diagnostic method.

Iron load is correlated with cardiac performance as detected by echocardiography [13]. It is reasonable that the myocardial iron content detected by MRI should have some correlations with ferritin level and echocardiographic parameters of cardiac performance [13, 14].

In this study, we aimed to evaluate the correlation between serum ferritin level and myocardial hemosiderosis, detected by T2*MRI, and also myocardial function, assessed by echocardiography.

\section{MATERIALS AND METHODS}

This study enrolled 84 patients with $\beta$-thalassemia major over a 2-year period (September 2010 to October 2012). These patients were undergoing regular follow-up in the hematology clinic of the pediatric ward at Shohada Hospital in Tehran. Thalassemic patients who had suffered from congenital heart disease, valvular heart disease, or infectious disease at the time of study were excluded. Sixty-three cases were finally included in the study. The Ethics Committee of the hospital approved the study, and all patients or their guardians gave informed consent. Each patient was entered into the study one time only. All patients had been receiving regular blood transfusion every 2 to 5 weeks to maintain a pre-transfusion hemoglobin level of $>9 \mathrm{~g} / \mathrm{dL}$. Transfusion therapy had been started before the age of 5 years in all patients. In addition, all patients were on regular chelation therapy according to their serum ferritin level (46 patients on oral deferasirox, 10 on defroxamine, and 7 on both deferipirone and defroxamine). Serial serum ferritin level was measured 1 week after blood transfusion using a standard enzyme-linked immunosorbent assay (ELISA). Serum ferritin level was defined as the mean value of the last 4 measurements. To evaluate the relationship between serum ferritin and cardiac function, ferritin levels were divided into $<1,000 \mathrm{ng} / \mathrm{mL}, 1,000-2,000 \mathrm{ng} / \mathrm{mL}$, and $>2,000 \mathrm{ng} / \mathrm{mL}$.

Complete echocardiography examination, including M-Mode, 2-dimensional, pulsed, and color Doppler was performed 1 week after blood transfusion in each patient. Cardiac systolic function was categorized according to left ventricular (LV) ejection fraction (EF) [15] as normal systolic function $(\mathrm{EF}>55 \%)$, mild systolic dysfunction $(45 \%<\mathrm{EF}$ $<55 \%)$, moderate systolic dysfunction $(30 \%<\mathrm{EF}<45 \%)$, and severe systolic dysfunction $(\mathrm{EF}<30 \%)$. Pulsed Doppler echocardiography analysis of mitral inflow velocities at an apical 4-chamber view was used to assess LV diastolic function [16, 17]. LV diastolic function was categorized as follows: normal, abnormal relaxation or grade 1 dysfunction, pseudo-normal or grade 2 dysfunction, and restrictive or grade 3 dysfunction. Echocardiography was performed by a single expert cardiologist who was unaware of $\mathrm{T} 2 *$ MRI findings and serum ferritin level.

MRI was performed within 1 to 2 weeks after blood transfusion. All MRIs were performed with $1.5 \mathrm{~T}$ scanners (Symphony, Siemens, Germany). Results of T2*MRI were categorized as normal myocardium $\left(\mathrm{T}^{*}>20 \mathrm{~ms}\right)$, mild myocardial involvement $\left(14 \mathrm{~ms}<\mathrm{T} 2^{*}<20 \mathrm{~ms}\right)$, moderate myocardial involvement $(10 \mathrm{~ms}<\mathrm{T} 2 *<14 \mathrm{~ms})$, and severe myocardial involvement (T2* $<10 \mathrm{~ms})[18,19]$.

Data were analyzed using SPSS software (version 16) to examine the relationship among serum ferritin level, cardiac function (echocardiography results), and cardiac iron load (T2*MRI results). We used one-way ANOVA, Kruskal-Wallis test, Mann-Whitney test, and the Spearman coefficient factor for statistical analysis. A $P$ value $<0.05$ was considered statistically significant.

\section{RESULTS}

Sixty-three patients were enrolled: 40 (63.5\%) women and $23(36.5 \%)$ men. Mean patient age was $23.7 \pm 5.1$ years with a range of 15 to 35 years.

\section{Echocardiography}

All 40 women (100\%) versus 19 of the $23(82.6 \%)$ men had normal LV systolic function $(P=0.024)$. LV diastolic function was not different between genders $(P=0.215)$. Evaluation of systolic and diastolic dysfunction showed that 12 of 63 patients had pure diastolic dysfunction with $\mathrm{EF} \geq 45 \%$, while only 2 patients had simultaneous diastolic and systolic dysfunction with $\mathrm{EF}<45 \%$, $(P=0.01$; Table 1$)$. There was no significant correlation between serum ferritin level and LV systolic $(P=0.994)$ or $\mathrm{LV}$ diastolic function $(P=0.475)$. 
Table 1. Distribution of diastolic dysfunction according to ejection fraction.

\begin{tabular}{|c|c|c|c|c|c|}
\hline Diastolic dysfunction grade & Normal & $\begin{array}{c}\text { Grade } \\
\text { I }\end{array}$ & $\begin{array}{c}\text { Grade } \\
\text { II }\end{array}$ & $\begin{array}{l}\text { Grade } \\
\text { III }\end{array}$ & Total \\
\hline Number of patients with $\mathrm{EF} \geq 45-50 \%$ & 48 & 2 & 7 & 3 & 60 \\
\hline Number of patients with $\mathrm{EF}<45 \%$ & 1 & 0 & 0 & 2 & 3 \\
\hline
\end{tabular}

Abbreviation: $\mathrm{EF}$, ejection fraction.

Table 2. Serum ferritin level according to MRI findings.

\begin{tabular}{lccrr} 
& \multicolumn{3}{c}{ Ferritin level $(\mathrm{ng} / \mathrm{mL})$} & Total \\
\cline { 2 - 4 } & $<1,000$ & $1,000-2,000$ & $>2,000$ & $52(100 \%)$ \\
Normal T2* MRI & $30(57.7 \%)$ & $12(23.1 \%)$ & $10(19.2 \%)$ & $11(100 \%)$ \\
Abnormal T2* MRI & $0(0 \%)$ & $4(36.4 \%)$ & $7(63.6 \%)$ & $63(100 \%)$ \\
Total & $30(47.6 \%)$ & $16(25.4 \%)$ & $17(27.0 \%)$ & \\
\hline
\end{tabular}

Table 3. Relationship between MRI and echocardiography findings.

\begin{tabular}{lccccc}
\hline & $\begin{array}{c}\text { Pure diastolic } \\
\text { dysfunction }\end{array}$ & $\begin{array}{c}\text { Mix systolic and } \\
\text { diastolic dysfunction }\end{array}$ & $\begin{array}{c}\text { Pure systolic } \\
\text { dysfunction }\end{array}$ & $\begin{array}{c}\text { Normal cardiac } \\
\text { function }\end{array}$ & Total \\
\hline Normal MRI count & 11 & 0 & 0 & 41 & 52 \\
Abnormal MRI count & 1 & 2 & 1 & 7 & 11 \\
Total & 12 & 2 & 1 & 48 & 63 \\
\hline
\end{tabular}

\section{T2* levels in MRI}

Table 2 demonstrates the correlation between serum ferritin level and cardiac T2*MRI. The frequency of abnormal cardiac MRI was $63.6 \%$ in patients with serum ferritin level $>2,000 \mathrm{ng} / \mathrm{mL}$, while it dropped to $36.4 \%$ in serum ferritin level of 1,000-2,000 ng/mL, and no patients with ferritin level $<1,000 \mathrm{ng} / \mathrm{mL}$ had an abnormal cardiac MRI $(P=0.001)$. T2*MRI detected the same percentage of cardiac siderosis in men and women: $17.3 \%$ of men ( 3 severe and 1 moderate siderosis) and $17.5 \%$ of women ( 3 severe, 1 moderate, and 3 mild siderosis) showed some degree of siderosis in the MRI $(P=0.5)$.

\section{MRI and echocardiography relationship}

Table 3 shows the correlation between echocardiography and $2^{*} \mathrm{MRI}$. Comparing echocardiography and MRI findings revealed no statistical difference between LV systolic function and cardiac siderosis $(P=1.00)$. However, we detected a significant difference between LV diastolic function and cardiac siderosis: of 52 patients with normal cardiac siderosis, 11 had abnormal diastolic function without any systolic dysfunction $(P=0.03)$.

\section{DISCUSSION}

The present study showed that 40 women versus 19 men had normal LV systolic function, and the difference between them was significant $(P=0.024)$, while both groups had a similar treatment protocol. These findings are similar to those by Hahallis et al. [20]. In their studies, in men and women with similar serum ferritin level and receiving a similar number of blood units, men had more LV systolic dysfunction, whereas LV diastolic function was similar in both genders. The reason for this gender difference may be genetic factors.

We found no significant correlation between serum ferritin level and cardiac systolic or diastolic function. There are differences among studies about the effect of serum ferritin level on cardiovascular function. For example, Bosi et al. [21] showed that LV systolic function was worse with serum ferritin level $>2,500 \mathrm{ng} / \mathrm{mL}$ than with the level $<1,000 \mathrm{ng} / \mathrm{mL}$. Silvilairat et al. [22] found that cardiac systolic function was normal when serum ferritin was $<2,500$ $\mathrm{ng} / \mathrm{mL}$. Other studies by Shahmohammadi et al. [23], Finazzo et al. [24], and Yapark et al. [25] were similar to our study. The difference between the various studies may be that there are different intervals between the occurrence of cardiac siderosis and the appearance of cardiac dysfunction.

The present data showed that higher serum ferritin were significantly correlated with lower T2*MRI $(P=0.001)$. These data are in agreement with previous studies [10-13, 26, 27]. Because of the effects of vitamin $\mathrm{C}$ deficiency and hepatitis on serum ferritin level (both are common in thalassemia), serum ferritin results do not reliably predict iron overload 
and cardiac siderosis except in a serial ferritin measurement profile $[5,9]$. T2*MRI had a high positive predictive value for anticipating cardiac dysfunction in asymptomatic TM patients $[9,13,28,29]$. This can alert the TM treatment team to use more intensive chelation therapy to prevent cardiac dysfunction for risky, asymptomatic TM patients.

Our study showed that there is no statistical difference between the degree of $\mathrm{T}^{*}$ abnormality in MRI and cardiac systolic function $(P=0.4)$; this is similar to previous studies and may justify using T2*MRI as an indicator of future systolic dysfunction [13, 27]. However, the interesting finding of our study was that 11 patients with pure cardiac diastolic dysfunction had normal T2*MRI and a low serum ferritin level $(P=0.03)$. Diastolic dysfunction of the heart usually appears prior to systolic dysfunction. Shahmohammadi et al. [23] showed that evaluation of diastolic cardiac function is useful for early detection of LV cardiac dysfunction. Ozbek et al. [30] showed that diastolic function can be impaired owing to cardiac siderosis even when $\mathrm{T}^{*}>20 \mathrm{~ms}$. The present study showed that echocardiography is able to diagnose heart diastolic dysfunction of thalassemia patients when T2*MRI findings are normal. Thus, it seems that echocardiography can diagnose cardiac problem in thalassemia patients earlier than T2*MRI.

There are several factors affecting cardiovascular function in thalassemia patients, such as genetic factors, endocrinopathy, regularity of iron chelation therapy, regularity of blood transfusion, and pulmonary hypertension. To prevent cardiac dysfunction, which is the most important cause of mortality and morbidity in TM patients, large-scale and multicenter investigations are needed to find effective factors. Cardiac siderosis is only 1 factor affecting cardiovascular function.

In conclusion, although there was no significant correlation between T2*MRI and echocardiographic findings, the results revealed that, even with a normal MRI $(\mathrm{T} 2 *>20$ $\mathrm{ms}$ ) and low serum ferritin level, diastolic dysfunction may be detected by echocardiography.

\section{Authors' Disclosures of Potential Conflicts of Interest}

No potential conflicts of interest relevant to this article were reported.

\section{REFERENCES}

1. Galanello R, Origa R. Beta-thalassemia. Orphanet J Rare Dis 2010;5:11.

2. Galanello R, Piras S, Barella S, et al. Cholelithiasis and Gilbert's syndrome in homozygous beta-thalassaemia. Br J Haematol 2001;115:926-8.

3. Cappellini MD, Cohen A, Eleftheriou A, Piga A, Porter J, Taher A, eds. Guidelines for the clinical management of thalassaemia, 2nd Revised ed. Strovolos, Cyprus: Thalassaemia International Federation, 2008.

4. Borgna-Pignatti C, Galanello R. Thalassemias and related disorders: quantitative disorders of hemoglobin synthesis. In: Greer JP, Foerster J, Lukens JN, Rodgers GM, Paraskevas F, Glader B, eds. Wintrobe's clinical hematology, 11th ed. Philadelphia, PA: Lippincott Williams \& Wilkins, 2004:1319-65.

5. Tanner MA, Galanello R, Dessi C, et al. Myocardial iron loading in patients with thalassemia major on deferoxamine chelation. J Cardiovasc Magn Reson 2006;8:543-7.

6. Borgna-Pignatti C, Cappellini MD, De Stefano P, et al. Survival and complications in thalassemia. Ann N Y Acad Sci 2005; 1054:40-7.

7. Queiroz-Andrade $M$, Blasbalg R, Ortega CD, et al. MR imaging findings of iron overload. Radiographics 2009;29:1575-89.

8. Karimi M, Borzouee M, Mehrabani A, Cohan N. Echocardiographic finding in beta-thalassemia intermedia and major: absence of pulmonary hypertension following hydroxyurea treatment in beta-thalassemia intermedia. Eur J Haematol 2009;82:213-8.

9. Modell B, Khan M, Darlison M, Westwood MA, Ingram D, Pennell DJ. Improved survival of thalassaemia major in the UK and relation to T2* cardiovascular magnetic resonance. J Cardiovasc Magn Reson 2008;10:42.

10. He T, Gatehouse PD, Smith GC, Mohiaddin RH, Pennell DJ, Firmin DN. Myocardial T2* measurements in iron-overloaded thalassemia: An in vivo study to investigate optimal methods of quantification. Magn Reson Med 2008;60:1082-9.

11. Fragasso A, Ciancio A, Mannarella C, et al. Myocardial iron overload assessed by magnetic resonance imaging (MRI)T2* in multi-transfused patients with thalassemia and acquired anemias. Eur J Intern Med 2011;22:62-5.

12. Wood JC. History and current impact of cardiac magnetic resonance imaging on the management of iron overload. Circulation 2009;120:1937-9.

13. Wood JC. Impact of iron assessment by MRI. Hematology Am Soc Hematol Educ Program 2011;2011:443-50.

14. Pengemail CT, Tsai CH, Wu KH, Hsu CC, Sheng TY. Improvement of cardiac function in thalassemia patients using deferiprone. Tzu Chi Med J 2007;19:192-9.

15. Gonzalez MM, Berg RA, Nadkarni VM, et al. Left ventricular systolic function and outcome after in-hospital cardiac arrest. Circulation 2008;117:1864-72.

16. Ozer N. Assessment of diastolic function. Biot, France: European Society of Cardiology, 2010. (Accessed January 17, 2014, at www.escardio.org/congresses/euroecho2010/Documents/teach ing-course-slides/euroecho2010-diastolic-function-ozer-135. pdf)

17. Zile MR, Brutsaert DL. New concepts in diastolic dysfunction and diastolic heart failure: Part I: diagnosis, prognosis, and measurements of diastolic function. Circulation 2002;105:138793.

18. Carpenter JP, He T, Kirk P, et al. On T2* magnetic resonance and cardiac iron. Circulation 2011;123:1519-28.

19. Di Tucci AA, Matta G, Deplano S, et al. Myocardial iron overload assessment by $\mathrm{T}^{*}$ magnetic resonance imaging in adult transfusion dependent patients with acquired anemias. Haematologica 2008;93:1385-8.

20. Hahalis G, Alexopoulos D, Kremastinos DT, Zoumbos NC. Heart failure in beta-thalassemia syndromes: a decade of progress. Am 
J Med 2005;118:957-67.

21. Bosi G, Crepaz R, Gamberini MR, et al. Left ventricular remodelling, and systolic and diastolic function in young adults with beta thalassaemia major: a Doppler echocardiographic assessment and correlation with haematological data. Heart 2003;89:762-6.

22. Silvilairat S, Sittiwangkul R, Pongprot Y, Charoenkwan P, Phornphutkul C. Tissue Doppler echocardiography reliably reflects severity of iron overload in pediatric patients with beta thalassemia. Eur J Echocardiogr 2008;9:368-72.

23. Shahmohammadi A, Davari PN, Aarabi Y, Meraji M, Tabib A, Mortezaeian H. Echocardiographic assessment of cardiac involvement in patients with thalassemia major: evidence of abnormal relaxation pattern of the left ventricle in children and young patients. Iranian Heart Journal 2006;7:31-6.

24. Finazzo M, Midiri M, D'Angelo P, et al. The heart of the patient with beta thalassemia major. Study with magnetic resonance. Radiol Med 1998;96:462-5.

25. Yaprak I, Aksit S, Ozturk C, Bakiler AR, Dorak C, Turker M. Left ventricular diastolic abnormalities in children with beta-thala- ssemia major: a Doppler echocardiographic study. Turk J Pediatr 1998;40:201-9.

26. Mazza P, Giua R, De Marco S, et al. Iron overload in thalassemia: comparative analysis of magnetic resonance imaging, serum ferritin and iron content of the liver. Haematologica 1995;80:398404.

27. Bayraktaroglu S, Aydinok Y, Yildiz D, Uluer H, Savas R, Alper H. The relationship between the myocardial $\mathrm{T} 2^{*}$ value and left ventricular volumetric and functional parameters in thalassemia major patients. Diagn Interv Radiol 2011;17:346-51.

28. Pennell DJ. T2* magnetic resonance and myocardial iron in thalassemia. Ann N Y Acad Sci 2005;1054:373-8.

29. Kremastinos DT, Farmakis D, Aessopos A, et al. Beta-thalassemia cardiomyopathy: history, present considerations, and future perspectives. Circ Heart Fail 2010;3:451-8.

30. Ozbek O, Acar K, Kayrak M, et al. Relationship between color $\mathrm{M}$-mode echocardiography flow propagation and cardiac iron load on MRI in patients with thalassemia major. Diagn Interv Radiol 2012;18:208-14. 